\title{
APROXIMACIÓN AL MODELO DE GESTIÓN DE TERRITORIO-MUSEO A PARTIR DE CASOS PRÁCTICOS ${ }^{[(]}$
}

\section{APPROACHING THE TERRITORY-MUSEUM MANAGEMENT MODEL FROM CASE STUDIES}

\author{
ANDREA BRINGAS HEREDIA ${ }^{(\star \star)}$ Y RUTH VICO MORENO ${ }^{[* \star *]}$ \\ D https://orcid.org/0000-0002-2960-3601 \\ andreabringas@gmail.com \\ Universidad de Alcalá (España) \\ (iD https://orcid.org/0000-0001-6500-1627 \\ ruthvimo@hotmail.com \\ Universidad de Alcalá (España)
}

\section{RESUMEN}

El reciente concepto de Territorio-museo surge en la segunda mitad de los años 90, como estrategia para definir un modelo de gestión basado en la musealización de un territorio con la finalidad de contribuir al desarrollo sostenible de un determinado espacio rural. En dicho modelo se enfatizan las intervenciones en la conservación del patrimonio natural y cultural, tangible e intangible; la participación activa y protagónica de la sociedad; y la implementación de un plan de interpretación territorial. En el presente trabajo se detallarán los orígenes del concepto en los ecomuseos y en las teorías de interpretación, se explicarán las características de los Territorio-museo y los elementos que lo conforman. Finalmente, se hará un análisis comparativo de tres casos en Italia, España y Argentina, con el objetivo de visibilizar las características compartidas y las diferencias, en el marco de la amplitud y variabilidad regional de este innovador concepto. Todo ello, permitirá presentar una breve discusión y extraer conclusiones

\section{PALABRAS CLAVE}

Territorio-museo; patrimonio; interpretación

\section{ABSTRACT}

The recent concept of Territory-museum arose in the second half of the $90 \mathrm{~s}$, as a strategy to define a management model based on the musealization of a territory, in order to contribute to the sustainable development of rural areas. In that model, the following are emphasized: interventions in the conservation of natural and cultural heritage, tangible and intangible; the active and leading participation of society; and, the implementation of a territorial interpretation plan. In the present work, the origins of the concepts of ecomuseums and theories of interpretation will be detailed, and the characteristics of the Territory-museum and the elements that are part of it, will be explained. Finally, there will be a comparative analysis of three cases in Italy, Spain and Argentina, in order to show the shared characteristics and differences, within the framework of the scope and regional variability of this innovative concept. All of this, will let to present a brief discussion and conclusions.

\section{KEYWORDS}

Territory-museum; heritage; interpretation

(*) El presente documento ha sido desarrollado a partir de la reelaboración de un trabajo de investigación para el curso de Gestión del Patrimonio en el Interior Peninsular desarrollado en el 2018 bajo la responsabilidad del Dr. Pedro Jimenez, como parte de la malla curricular del Máster en Arqueología y Gestión del Patrimonio en el Interior Peninsular de la Universidad de Alcalá.

(**) Magíster en Arqueología y Gestión del Patrimonio en el Interior Peninsular por la Universidad de Alcalá, Licenciada en Arqueología por la Pontificia Universidad Católica del Perú, y con estudios en Relaciones Comunitarias y Responsabilidad Social en la Universidad ESAN. Tiene experiencia en gestión del patrimonio arqueológico, de desarrollo y de responsabilidad social, relaciones comunitarias y procesos de incidencia política. Ha realizado diversas consultorías para los sectores público y privado.

(***) Magíster en Arqueología y Gestión del Patrimonio en el Interior Peninsular por la Universidad de Alcalá, Graduada en Comunicación audiovisual por la Universidad Rey Juan Carlos de Madrid, y con estudios en Historia en la Universidad de Alcalá. Tiene experiencia en el ámbito privado (Técnico en empresa) y en el ámbito público de la Arqueología (proyectos universitarios), y en gestión de proyectos culturales como comunicadora. 
devenir Vol. 7, N¹3, ENERO - JUNIO 2020, PP. 59-76 - ESTUDIOS I ISSN 2312-7562 | E-ISSN 2616-4949

UNIVERSIDAD NACIONAL DE INGENIERÍA, LIMA

doi: https://doi.org/10.21754/devenir.v7i13.762

\section{Introducción}

A partir del cambio de paradigma que significó el concepto de "museo al aire libre" y las propuestas de intervención patrimonial como los ecomuseos, el patrimonio, la población y el desarrollo sostenible son variables estrechamente vinculadas. En ese marco, y bajo la estrategia de interpretación patrimonial, se crea el concepto de Territorio-museo en la segunda década de los años 90. Las primeras publicaciones donde se explica este modelo de gestión territorial para zonas rurales, aparecen en el año 2000 y la discusión sigue abierta. Existen algunos ejemplos de implementación de este modelo, con algunas variantes en el nombre, en diversas regiones. Con este trabajo, se pretende contribuir a la discusión del concepto a partir de la revisión de tres ejemplos de Territorio-museo.

En primer lugar, luego de explicitar los objetivos y la metodología, se presenta un marco normativo internacional que visibiliza el énfasis de algunos componentes de los Territorio-museo como la participación protagónica de la población, la interpretación, el desarrollo sostenible territorial, entre otros. En segundo lugar, se hace un breve resumen de los antecedentes que se toman para la creación del modelo de gestión: ecomuseos e interpretación; $y$, en tercer lugar, se detalla el modelo y sus características principales. En cuarto lugar, se presentan los casos de implementación de Territorio-museo y se hace un breve análisis y discusión. Finalmente, se presentan algunas conclusiones.

\section{Objetivo}

El presente trabajo tiene por objetivo, comparar casos del modelo de gestión para ámbitos rurales, denominado "Territorio-museo" (TM) con la finalidad de realizar una aproximación a su aplicación práctica. Para ello, se parte de tres casos reales de distintos países, Italia, Argentina y España, que cuentan con territorios musealizados en zonas históricas y naturales, cuyas características se evaluarán con la metodología propuesta a continuación. Se espera que los resultados contribuyan a enriquecer la definición variable de los TM y sugerir retos y líneas de trabajo en la gestión del patrimonio natural y cultural en espacios abiertos.

\section{Metodología}

La investigación tiene un carácter teórico. A partir de la literatura, se revisará el concepto de Territorio-museo y sus antecedentes, y se presentarán los casos prácticos de implementación de este tipo de intervención patrimonial en distintos contextos. A través de la comparación de las características de los casos, se realizará una discusión sobre la aplicación práctica de los TM. Para la comparativa, se evaluará la presencia o ausencia de las características propuestas para los Territorio-museo, siendo"1 punto"o "0 punto" según corresponda:

\section{Estructura organizativa}

2. Plan de interpretación territorial

3. Participación activa y protagónica de la población

4. "Puerta"

5. "Ventanas temáticas"

6."Caminos temáticos"

\section{Programación de eventos}

8. Oferta de servicios 
Tabla 1. Puntaje de un Territorio-museo (TM) según sus características.

\begin{tabular}{ll}
\hline \multicolumn{1}{c}{$\begin{array}{c}\text { Número de } \\
\text { características }\end{array}$} & Cumplimiento del modelo de TM \\
\hline Todas: 8 puntos & Se cumple totalmente \\
Entre 5 y 7 puntos & Se cumple parcialmente o falta información \\
Entre 0 y 3 puntos & No se cumple o falta información \\
\hline Elaboración propia, 2019. &
\end{tabular}

Para el presente trabajo, se propone que si los casos reportan la presencia de estas 8 características, el modelo de gestión de TM se cumple; si los casos tienen la presencia de al menos, 5 características, el modelo se cumple parcialmente; y si los casos demuestran la presencia de 3 o menos características, el modelo no se cumple (ver Tabla 1).

\section{Marco normativo internacional}

Dado que la propuesta de TM tiene bases en las relaciones entre los conceptos de patrimonio, territorio, paisaje, interpretación, población y desarrollo, es importante mencionar cómo se expresan estas relaciones en los lineamientos internacionales. En la Carta de Lausana (1990), por ejemplo, se llama la atención sobre el rol de la población en la conservación integral del patrimonio arqueológico. Y en la Carta de Cracovia (2000) se enfatiza la relación entre el patrimonio, el territorio y el paisaje. Este último, entendido como el resultado de múltiples interacciones, las mismas que deben ser consideradas en conservación y desarrollo. En la Convención Europea del Faro (2005) se menciona la interpretación como estrategia para fomentar el patrimonio cultural.

En la década de los años 90 se desarrolló una iniciativa sobre ordenación del territorio denominada "Estrategia Territorial Europea" que tuvo por finalidad "... ser un marco de referencia común para un territorio europeo sin fronteras interiores, pero reconociendo su diversidad regional, cultural y geográfica". Y que además: "Podrá constituirse en la herramienta que dote de coherencia territorial a las políticas sectoriales y maximice su eficacia..." (Mora \& Pimienta, 1996-2003, p.702). Con esa premisa, se realizaron reuniones y acuerdos entre países en diferentes años, entre los cuales, destacan: la reunión de Leipzig (1994), en la cual se establecieron acuerdos de principios políticos y trataron temas como el “...sistema urbano equilibrado y policéntrico; igualdad de acceso a infraestructuras y al conocimiento; gestión prudente y desarrollo del patrimonio natural y cultural..." (Mora \& Pimienta, 1996-2003, p.704). La siguiente reunión importante es la de Noordwijk (1997) en la que se realiza el primer borrador oficial de la ETE y se tratan los temas de "... aspectos territoriales de dimensión europea mediante análisis DAFO..., impacto de las políticas comunitarias de mayor incidencia territorial... [y] trabajos de análisis territorial..." (Mora \& Pimienta, 1996-2003, p. 704).

Finalmente, en la reunión europea celebrada en Potsdam (1999) se aprueba el documento, se adopta la Estrategia Territorial Europea y se enfatiza sobre el "...desarrollo equilibrado y sostenible, mediante el refuerzo de la cohesión económica y social, como objetivo principal que integra a los planteados anteriormente [a las reuniones de 1994 y 1997]..." (Mora \& Pimienta, 1996-2003, p. 704).

Como se verá más adelante, la propuesta del modelo de gestión patrimonial de TM coloca a la población como protagonista del modelo aplicado. Asimismo, se utiliza 
devenir Vol. 7, N¹3, ENERO - JUNIO 2020, PP. 59-76 - ESTUDIOS I ISSN 2312-7562 | E-ISSN 2616-4949

UNIVERSIDAD NACIONAL DE INGENIERÍA, LIMA

doi: https://doi.org/10.21754/devenir.v7i13.762

la interpretación como estrategia de presentación del patrimonio a los visitantes, a través de los itinerarios. Y, dado que la unidad de intervención es el territorio, la consideración del paisaje y la búsqueda del desarrollo sostenible son fundamentales. Específicamente, la propuesta de TM utiliza los siguientes aspectos del documento mencionado líneas arriba:

(...) la salvaguarda y la puesta en valor del patrimonio cultural y natural se cuentan entre las principales líneas de actuación(...) destaca la importancia del patrimonio en la configuración de las identidades territoriales europeas y la necesidad de aplicar criterios de «gestión creativa» para su puesta en valor (Padró \& Miró, 2002, p. 73).

\section{Marco conceptual de los Territorios-museo}

A partir de la segunda mitad del siglo XIX surgen los «museos al aire libre», en oposición a la visión tradicional de un edificio con objetos museables.

El objetivo era conservar la identidad cultural de unos pueblos que estaban gravemente amenazados debido al desarrollo de la industrialización y el urbanismo. Este cambio conceptual en la museología se asocia al arqueólogo sueco Artur Hazelius, el cual fundó en Escandinavia en el año 1873, el primer museo de etnografía. Esto supuso el punto de partida del Nordiska Museet, inaugurado en 1880 y que contaría once años después con una sección al aire libre que recibió el nombre de Skansen (Delgado \& Martín, 2016, p.31).

Dicho museo se trataba de la recreación de la vida de Suecia a través de construcciones de viviendas y recreaciones de actividades tradicionales. Por su parte, en Estados Unidos surgen:

(...) medidas de protección y apertura pública de sus parques naturales, convertidos en una de las imágenes de la cultura nacional, en la órbita de movimientos de retorno al medio rural tradicional. Posteriormente, Henry Ford promovió y financió la creación de Greenfield Village [un pueblo-museo del medio Oeste recreado](...) con fines pedagógicos y de ocio cultural (Ángeles, 2007, p.136).

Más adelante, hacia la segunda mitad del siglo XX, la UNESCO fundó el Consejo Internacional de Museos (ICOM) dedicada al ámbito de los museos, cuyo primer director fue Henri Riviere, impulsor de la Nueva Museología, "(...) [sobre los principios del ecomuseo] entre 1947 y 1967, como museos cuya principal característica suponía presentar una síntesis integradora de las relaciones entre el hombre y su medio natural en el tiempo y en el espacio desde una aproximación interdisciplinar..." (Ángeles, 2007, p.136). Así:

(...) Mientras que el museo tradicional se ocupa de la adquisición, conservación, estudio, valorización y exhibición de testimonios materiales del hombre y de su ambiente, el ecomuseo centra la atención en el territorio como elemento intrínsecamente ligado a los procesos sociales. Además, a diferencia del museo tradicional que se caracteriza por la exposición de su contenido a un público, el ecomuseo hace de la población misma uno de sus elementos relevantes (Borghi, 2017, p. 252).

Esta propuesta enfatiza la musealización del territorio mismo y se diferencia de la propuesta de los "museos al aire libre" en que:

(...) No trataba sólo de potenciar una visión idílica y nostálgica del mundo rural, sino que el concepto de Ecomuseo debía convertirse en elemento de refuerzo de la memoria colectiva de las comunidades, a partir de esta base, concebirse como un instrumento para el crecimiento económico, social y político de la sociedad de la que surge (Ángeles, 2007, pp. 137-138). 
Como se mencionó líneas arriba, otro concepto desarrollado hacia la segunda mitad del siglo XX, y que ha sido un insumo fundamental para la propuesta de los TM, es la interpretación. En sus inicios, esta estrategia se implementó en los parques naturales de Estados Unidos y, posteriormente, se utilizó en el ámbito del patrimonio cultural. La primera definición publicada de 1957 señala: "La interpretación es una actividad educativa que pretende revelar significados e interrelaciones a través del uso de objetos originales, por un contacto directo con el recurso o por medios ilustrativos, no limitándose a dar una mera información de los hechos..." (Tilden, 2006, pp. 110-111, en: Ruiz, 2010, p.167). Al respecto de la dimensión educativa presente en el concepto, se indica que «....se prestó a muchas confusiones, ... El mismo Freeman Tilden declaró más tarde, ..., que, si tuviese que revisar de nuevo su libro, comenzaría por "es una actividad recreativa"...» (Morales, 1998, p. 151).

Por un lado, se entiende que la interpretación se refiere a explicar, comunicar, traducir, revelar significados propios de un ámbito académico para uno no académico. $Y$, por otro, la interpretación toma distancia de la actividad educativa (se deduce la educación formal) para relacionarse con la recreación, lo que sugiere una contraposición de términos educación formal versus recreación. En este mismo sentido, se expresa:

(...) La interpretación del Patrimonio tiene los mismos intereses y objetivos que ciertas modalidades de educación ambiental; pero se diferencia de ellas; primero por el método, si bien, a veces, puede coincidir. La segunda diferencia son los destinatarios, las actividades de difusión [entendidas como «educativas»] van dirigidas a grupos organizados y estructurados para un fin educativo; mientras que las actividades de interpretación van dirigidas a visitantes fortuitos y voluntarios (Ruiz, 2010, p. 169).

Sin embargo, otros autores consideran que entre los fines de la interpretación, están los educativos: «... con esto, podemos decir que la interpretación es un método para la presentación, comunicación y explotación del patrimonio, con el objetivo de aprehensión y utilización del mismo con finalidades culturales, educativas, sociales y turísticas» (Padró, 1996, p. 9).

Otra definición importante es aquella que menciona que la interpretación es «...el arte de explicar el lugar del hombre en su medio, con el fin de incrementar la conciencia del visitante acerca de la importancia de esa interacción, y despertar en él un deseo de contribuir a la conservación del ambiente» (Aldridge, 1973, pp. 22-24, en: Morales, 1998, p. 2). Aquí, se destacan, además de la ubicación in situ (al igual que los ecomuseos), los efectos actitudinales esperados de la interpretación orientados hacia una participación activa en la conservación.

Siguiendo el esquema de cualquier proceso comunicativo, los elementos fundamentales de un proceso interpretativo son el intérprete o emisor, el mensaje y el destinatario o receptor. Existe una amplia literatura al respecto de las cualidades, roles y conocimientos de los intérpretes, del contenido y la calidad de los mensajes interpretativos, atractivos y emotivos. Sobre esto último, se señala:

(...) Es por ello que para entrar en sintonía e interpretar los mensajes y símbolos de dichos objetos precisamos de un intermediario, un especialista conocedor que sea capaz de aproximar el mensaje a elementos o códigos que la población actual conozca, sin variar ni modificar el sentido u objetivo comunicativo (Nieto, 2018, p. 129).

También existen manuales y literatura diversa enfocada a diseñar mensajes interpretativos sobre la base de un guion y en función de los distintos públicos, así como el estudio de perfiles y contextos de los públicos con la finalidad de asegurar la eficacia de las intervenciones. La interpretación del territorio en el modelo de gestión de un TM, supone prestar más atención a estos temas específicos. 
devenir Vol. 7, N¹3, ENERO - JUNIO 2020, PP. 59-76 - ESTUDIOS I ISSN 2312-7562 | E-ISSN 2616-4949

UNIVERSIDAD NACIONAL DE INGENIERÍA, LIMA

doi: https://doi.org/10.21754/devenir.v7i13.762

\section{Propuesta de intervención patrimonial: Territorio-museo}

El concepto de TM se desarrolló en conjunto con el concepto de "Museo abierto" en el marco de un proyecto de cooperación entre Italia y España, financiado por la Dirección General de Política Regional de la UE, en los años 90 del pasado siglo. Los conceptos surgían como respuesta a la necesidad de crear instrumentos de gestión del patrimonio desde una visión territorial, para un uso social del patrimonio y para el desarrollo local del entorno en el que éste se englobara (Miró, 2009).

Como explica Miró: "Respecto al concepto Territorio museo [de Alghero, en particular, caso italiano que se verá en extensión en el siguiente apartado], originalmente se trataba de un concepto de puertas adentro. Es decir, lo utilizamos como concepto para significar un modelo de gestión, no tenía intención de convertirse en una marca cultural, aunque luego acabó siéndolo" (correo electrónico del 14 de octubre de 2019). Por tanto, a raíz de proyectos como el de Alghero, en Cerdeña, Italia, iniciado en 1996, se empiezan a definir los TM, en este caso, para incidir en el desarrollo económico local de un territorio culturalmente muy rico.

La propuesta de modelo de gestión patrimonial de TM, aunque válida para ámbitos urbanos, se aplica principalmente en ámbitos rurales, y se basa en los conceptos de "ecomuseos" e"interpretación":

(...) [el concepto de TM] entronca con la herencia de los ecomuseos franceses y la tradición anglosajona de los planes de interpretación... [además, señala que, con este concepto,] pretendemos dar respuesta al reto de la gestión creativa del patrimonio que propone la ESDP [se refiere al documento de la Estrategia Territorial Europea] (Miró, 2000, p.9).

Siguiendo esto último y, en el marco del desarrollo sostenible, el autor enumera tres valores que pueden ser fomentados a través de la gestión patrimonial:

(...) Valor identitario: el patrimonio puede actuar o actúa como elemento generador de imagen y de identidad territorial.

Valor económico: la puesta en valor del patrimonio puede generar nuevas oportunidades de negocio $y$, por tanto, convertirse en un yacimiento de empleo y una nueva fuente de ingresos para el territorio.

Valor social: el desarrollo de un proyecto de puesta en valor del patrimonio puede contribuir a mejorar la calidad de vida de la población... (Padró \& Miró, 2002, p. 63; Miró, 2010, p. 34).

El autor sugiere dos aspectos positivos de la propuesta de TM: su aplicación en zonas rurales con un rico patrimonio tangible e intangible, y su potencial para desarrollar propuestas de «marcas-territorio». En ese sentido, señala que el TM tiene dos sentidos (ver Tabla 2).

Tal y como se mencionó, una de las bases de la propuesta de TM es la interpretación aplicada al territorio. Para el autor, es necesario considerar, entre otros, los siguientes aspectos:

- ¿qué se conserva y qué no se conserva?

- ¿qué prioridades de restauración hay?,

- ¿qué tipo de actividades se priorizan (o se subvencionan)?,

- ¿qué mensaje se da desde el patrimonio (histórico, científico, ideológico, emotivo...)?

- ¿a qué segmentos de público se debe dirigir la oferta? 
Tabla 2. Formas de visita de un Territorio-museo.

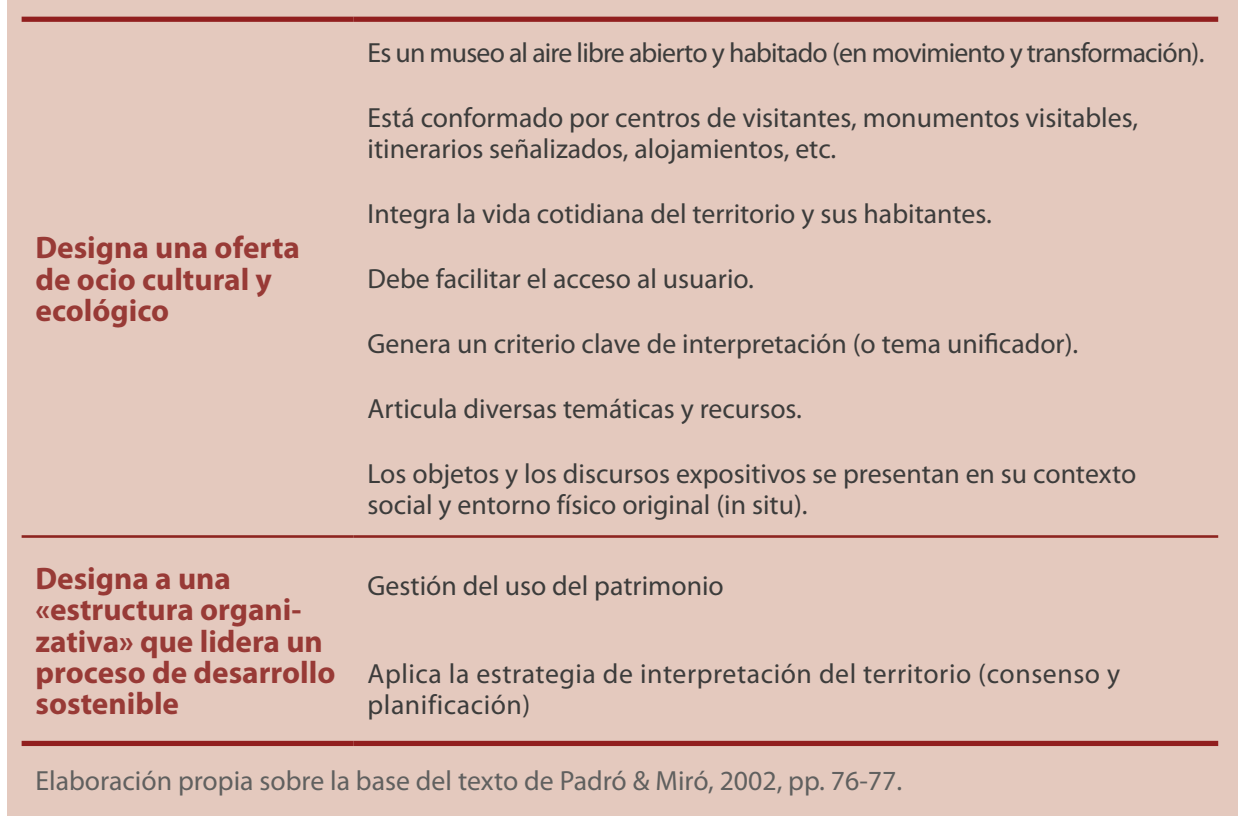

Tabla 3. Estructura modelo de un Territorio-museo.

\begin{tabular}{lll}
\hline \multicolumn{1}{c}{ Lugar } & \multicolumn{1}{c}{ Descripción } & \multicolumn{1}{c}{ Misión } \\
\hline $\begin{array}{l}\text { La puerta del Territo- } \\
\text { rio-museo }\end{array}$ & $\begin{array}{l}\text { Primer contacto entre usuario y territorio } \\
\text { (espacio de inmersión). }\end{array}$ & $\begin{array}{l}\text { Dar a conocer la estructura } \\
\text { y servicios del TM }\end{array}$ \\
Las ventanas temáticas & $\begin{array}{l}\text { Focalizan el discurso por temas desarrolla- } \\
\text { dos según el concepto clave de interpre- } \\
\text { tación. }\end{array}$ & $\begin{array}{l}\text { Dar las claves para } \\
\text { disfrutar de los recursos } \\
\text { vinculados a la temática } \\
\text { de la ventana. }\end{array}$ \\
Los eventos & $\begin{array}{l}\text { Programación continua de eventos (jorna- } \\
\text { das gastronómicas, ferias, festivales, etc.) }\end{array}$ & \\
Servicios & $\begin{array}{l}\text { Utilización como marca permite vincular } \\
\text { la imagen del TM con servicios para usua- } \\
\text { rios (transporte, alojamiento, restaurantes, } \\
\text { comercios, entre otros) }\end{array}$ & \\
\hline Elaboración propia sobre la base del texto de Miró, 2002, pp. 77-78; Miró \& Padró, 2000.
\end{tabular}

- ¿qué patrimonio debe gestionar o adquirir la administración?

- ¿qué costumbres, tradiciones... se pretende recuperar o salvaguardar?,

- ¿qué monumentos se hacen accesibles y de qué manera?,

- ¿cómo se garantiza la rentabilidad de las inversiones en patrimonio? (Padró \& Miró, 2002, p. 75; Miró, 2010, p.33)

A continuación, se presenta la estructura modelo de un TM (ver Tabla 3): 
devenir Vol. 7, N¹3, ENERO - JUNIO 2020, PP. 59-76 - ESTUDIOS I ISSN 2312-7562 | E-ISSN 2616-4949

UNIVERSIDAD NACIONAL DE INGENIERÍA, LIMA

doi: https://doi.org/10.21754/devenir.v7i13.762

\section{Aplicación de casos:}

\section{Caso 1. Territorio-museo de Alghero, Cerdeña (Italia)}

Para la explicación de este caso, además de lo publicado, se ha contado con información proporcionada por Manel Miró a través de correos electrónicos compartidos a propósito del presente artículo.

El territorio de Alghero, definido por montañas y llanuras verdes en la costa noroeste de Cerdeña, contenía una gran variedad cultural: tradiciones artesanales o gastronómicas, particularismos lingüísticos, arquitecturas populares, estrategias productivas peculiares, conjuntos monumentales, restos arqueológicos, obras de arte y otras manifestaciones culturales. Sin embargo, el turismo masivo de sol y playa estaba haciendo peligrar dicha identidad cultural al imponerse esta forma de vida insostenible, además de provocar un aumento de la delincuencia. La conclusión era que Alghero necesitaba un turismo más intelectual y menos estacional para ser más equitativo a lo largo del año, y eso se podía lograr gracias a su potencial cultural. A partir del análisis de la situación del territorio por parte del proyecto y de la población, se concluyó la necesidad de potenciar la conservación del patrimonio con un TM (Miró \& Padró, 2000).

La riqueza de Alghero se reparte entre patrimonio natural y patrimonio histórico, con diversas épocas y culturas pasadas que han dejado vestigios en el territorio. Por un lado, hay un gótico tardío en la Barceloneta, cuando este terreno pertenecía a la Corona de Aragón española, o el conjunto de nuraghes o torres defensivas del primer milenio a. C. (Fig. 1), de las que se conservan unas 100 torres a lo largo de varios kilómetros. Además, los romanos utilizaban estas costas, donde estaría el puerto natural más conocido del Mediterráneo. En cuanto al patrimonio natural, hay numerosas calas, grutas, acantilados y una galería subterránea de más de 2500 metros. Todo ello requería de estructuras museísticas y de un buen plan de interpretación, porque hasta entonces solo trabajaban con el patrimonio los guías turísticos (Miró \& Padró, 2000) (ver Figura 1).

La participación de la sociedad local se plasmó en los comerciantes del lugar que se comprometieron a embellecer el paisaje urbano. También participaron representantes del sector turístico y de empresas agroalimentarias.

Este TM recurrió a una frase como marca para resumir su potencial: «Alghero: la isla catalana de Cerdeña», pues eso es precisamente lo que hace a este territorio tan particular, como se puede ver en sus tradiciones populares, en el arte y la arquitectura catalanas. Partiendo de este concepto se extrajeron cuatro temáticas:

1. Isla cultura, contenedora del patrimonio eclesiástico

2. Isla arqueología, contenedora del núcleo de las nuraghes

3. Isla naturaleza, contenedora de todo el espacio natural y la galería subterránea

4. Isla fortaleza, contenedora de las murallas, y los recorridos por ellas (Miró \& Padró, 2000).

Para la interpretación de tantos espacios y recorridos se necesitaban centros visitables museísticos, cuya puerta al TM sería una de las torres conservadas, lugar que daría la bienvenida al usuario y otorgara una visión global del patrimonio natural y cultural de toda la ciudad. Esta sería la motivación para que desde ahí se quisiera seguir visitando el resto del conjunto. Por otro lado, se habilitó el mayor Centro de Interpretación en otra de las torres, con una exposición de la evolución urbana histórica de Alghero. Y, por último, habría un museo en la iglesia más destacada y mejor conservada con los restos arqueológicos, sobre todo eclesiásticos, de distintas épocas. 


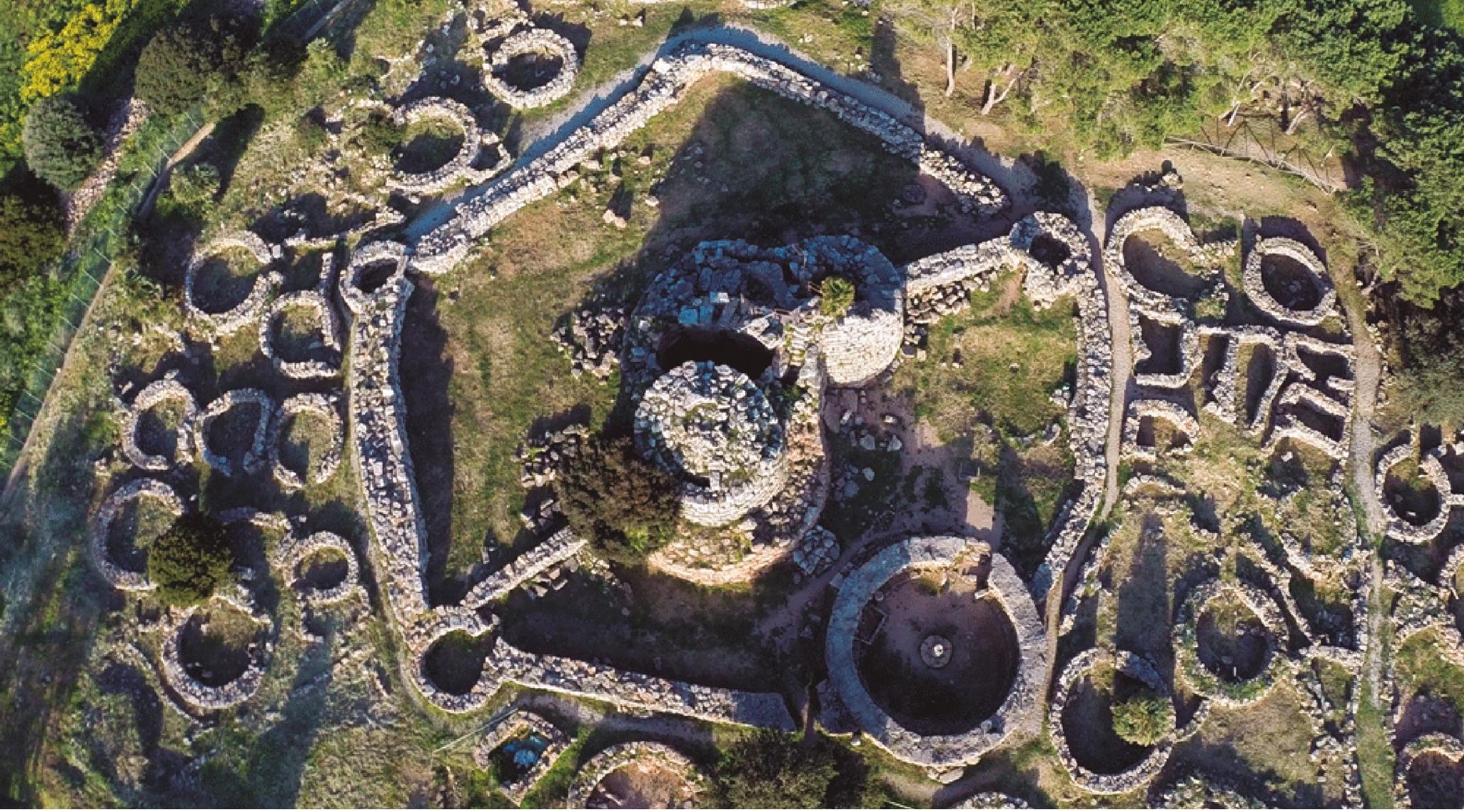

No solo la creación del TM cambió en los primeros años de funcionamiento el panorama turístico de la isla, pues el turismo era su principal fuente de ingresos, sino que se pretendían otros logros positivos, como la creación de nuevos puestos de trabajo para jóvenes desempleados, quienes se encargarían de la gestión de los distintos centros. A pesar de todo ello, seguían persistiendo problemáticas como: la falta de una estructura central de gestión territorial, puesto que había demasiadas unidades y falta de coordinación entre los centros y las administraciones. Ejemplos de ello eran los fallos en la señalización del recorrido, la falta de delimitación de las zonas de aparcamiento o que no se alcanzara un consenso en las estrategias de promoción. Como recalcan Miró y Padró, tiempo después de comenzarse la creación del proyecto y del concepto de TM en Alghero, éste se difuminaba:

Lejos queda la idea central que dio origen al proyecto: la necesidad de colocar el respeto al patrimonio cultural y natural, en el centro de las preocupaciones por mejorar la calidad de vida de los ciudadanos a partir de la implementación de unas políticas de desarrollo sostenible, y la creación de unos mecanismos de gestión que permitan, de una manera eficaz, la participación de la sociedad civil y de los agentes económicos en los procesos de ordenación del territorio (Miró \& Padró, 2000).

\section{Caso 2. Museo Integral de la Reserva de la Biosfera de Laguna Blanca (Argentina)}

Este proyecto se denomina Museo Integral de la Reserva de la Biosfera de Laguna Blanca, fundado en 1997 y dependiente de la Universidad Nacional de Catamarca, en Argentina. Además de la publicación científica, para exponer el caso se ha contado con la información publicada en la red de Facebook oficial de este TM.

Aquí, sus creadores definen el proyecto como un «Museo territorial», en contraposición a la tradicional definición del museo-edificio como espacio cerrado, pues aquí el objeto musealizable es la reserva protegida, es decir, el propio territorio: el entorno, la población, las tradiciones, los recursos, la fauna y la flora.

Esta zona tiene 5000 años de historia y en ella viven unos 600 habitantes, la mayoría ganaderos-agricultores o dedicados a la textilería como actividad económica con una larga trayectoria, así como la necesidad de proyectar y proteger su forma de sustento.

Figura 1. Sitio nurágico de Palmavera en Alghero. Recuperado de https://totalguer.com/en/area-interesse/al-cittadino/cultura/siti-archeologici/, 2019 


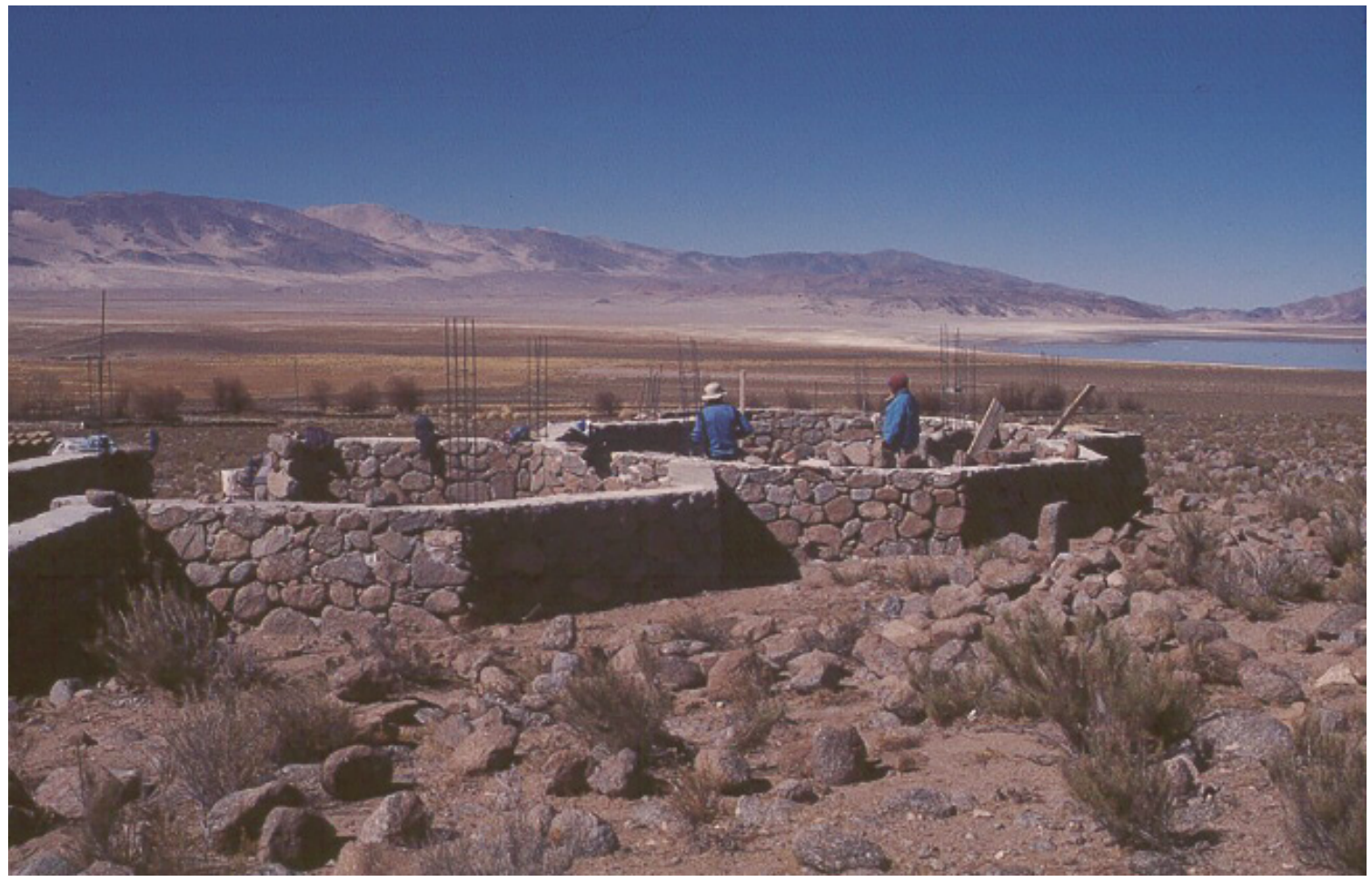

Figuras 3. Construcción del Centro de Recepción e Interpretación (CRI). Recuperado de https://www.facebook.com/pg/MuseoIntegralLB/photos/, 2019/

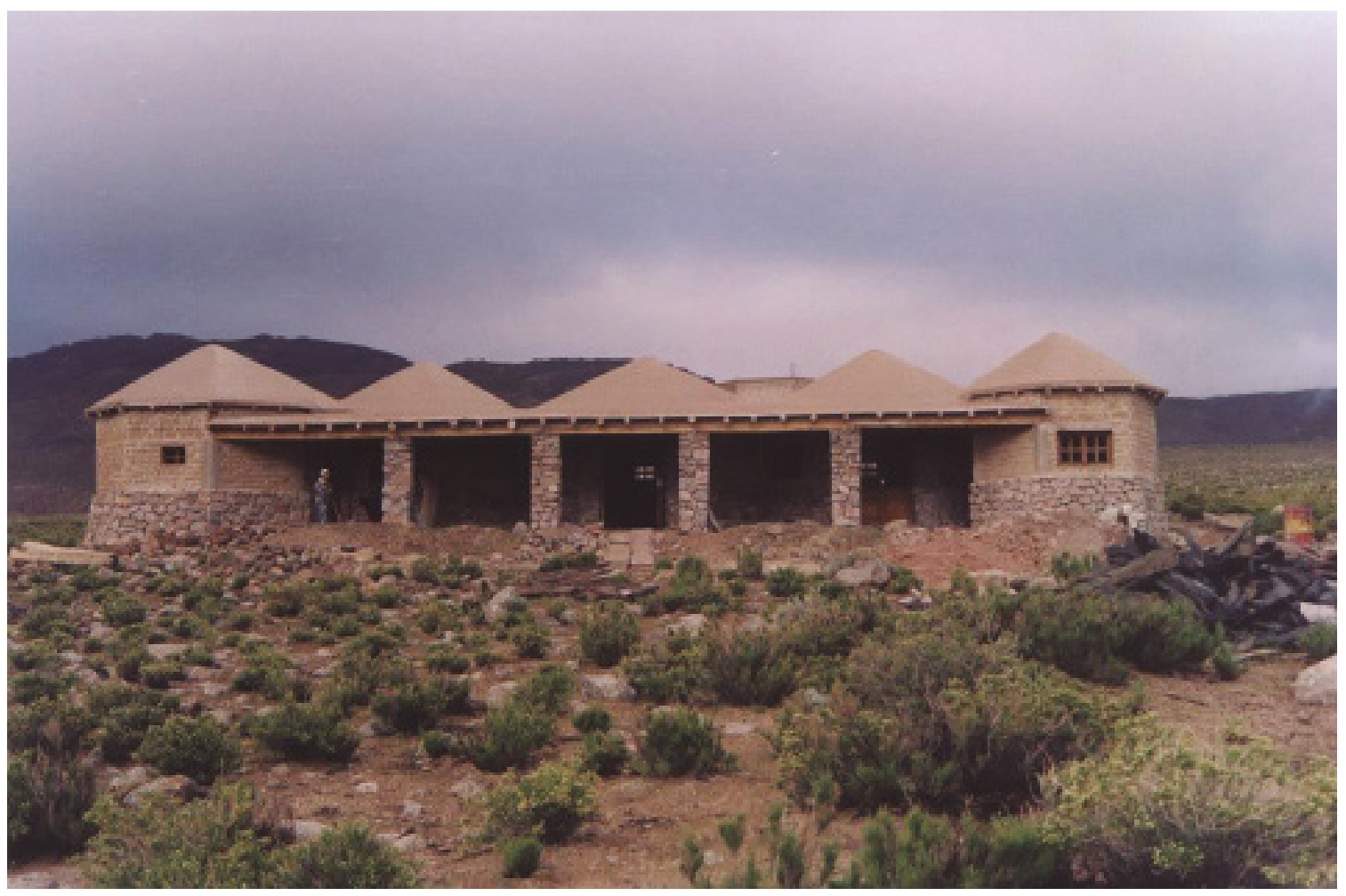

Figuras 4. Resultado final de la construcción del Centro de Recepción e Interpretación (CRI). Recuperado de https://www.facebook. com/pg/MuseolntegralLB/photos/, 2019. 
devenir Vol. 7, N¹3, ENERO - JUNIO 2020, PP. 59-76 - ESTUDIOS I ISSN 2312-7562 | E-ISSN 2616-4949

UNIVERSIDAD NACIONAL DE INGENIERÍA, LIMA

doi: https://doi.org/10.21754/devenir.v7i13.762

5. Circuitos por los sitios con arte rupestre, en concreto los lugares que contienen pictografías y petroglifos que expresan el desarrollo estético de la región.

6. Un mercado artesanal con productos del entorno y la participación de la población.

7. Trama de Sitios Panorámicos de Interpretación que parten del CRI (Fig. 2) y de un centro de información turística, que constituyen miradores a todo el TM en cuanto a la intención de acercar a los visitantes a la comprensión global de la reserva, a sus procesos naturales y socioculturales.

La propuesta de museo abierto ha pretendido unir territorio y comunidad, con proyectos participativos variados en colaboración con las poblaciones locales y con sus instituciones para dar a conocer el patrimonio y fomentar su sostenibilidad. Además de los distintos centros y espacios visitables, se han puesto en marcha acciones como la rehabilitación de paleotecnologías agrícolas, el desarrollo artesanal, textil y cerámico de tradición histórica, el desarrollo del turismo arqueológico para dar a conocer la profesión del Arqueólogo y hacerla interpretable, y también una línea de enseñanza sobre Historia local, educación e identidad (Delfino, et al, 2012) (ver Figura 3 y 4).

A través de redes sociales como Facebook, el Museo Integral también ofrece noticias de sus actividades, así como el resumen e información de sus centros y circuitos. Este TM está en continuo movimiento con la celebración de aniversarios conmemorativos dentro de la reserva, la participación voluntaria de investigadores internacionales, conferencias en la Universidad de Catamarca sobre la región de Laguna Blanca, actividades para todas las edades sobre producción artesana local y convocatorias de la comunidad local a distintas fiestas anuales.

\section{Caso 3. Territorio-museo de El Condado-Jaén (España)}

"Condado Jaén Territorio museo" es un proyecto cultural y turístico que parte de la iniciativa de ocho municipios y la Asociación para el Desarrollo Rural de la Comarca de El Condado (ASODECO), para poner en valor y potenciar la historia, la tradición y el desarrollo rural de los pueblos de esta región. Para ello se ha construido en cada uno de los ocho territorios un museo o centro de interpretación con visitas guiadas a diversos yacimientos, monumentos y parajes naturales, que funcionan desde el año 2012. A continuación, se describe información específica del proyecto proporcionada por Lorenzo Sáez Laut, Técnico Comarcal de Cultural y Género de El Condado de Jaén, a partir de una entrevista telefónica.

El Condado de Jaén era una zona deprimida que reclamaba la preservación de su entorno rural, de sus recursos naturales y su economía, predominantemente agropecuaria. Programas como Leader o el Fondo Europeo Agrícola de Desarrollo Rural (FEADER) de la Unión Europea, que elaboran estrategias de desarrollo rural con asociaciones públicas o privadas, ejecutaron, junto a ASODECO y la Junta de Andalucía, una estrategia de aprovechamiento de estos recursos, dentro de la cual uno de los puntos clave era la creación del TM. Previamente se realizó un análisis DAFO de El Condado desde todos los ámbitos de actuación posibles. Aquí se citan aspectos relativos a la difusión y conservación del Patrimonio como la inexistencia de un inventario arqueológico o de museos regionales, la carencia de estudios y excavaciones a pesar de la profusión de yacimientos y restos defensivos de diversas épocas, o las amenazas de ruina total de algunos monumentos históricos. Estas cuestiones no eran acordes con la fuerte identidad histórica y el rico paisaje rural y natural de los pueblos, además de las numerosas piezas arqueológicas coleccionadas, pero no exhibidas, en espera de la creación de un espacio de difusión e interpretación para dar a conocer todo este patrimonio a la sociedad (ASODECO, 2019). 


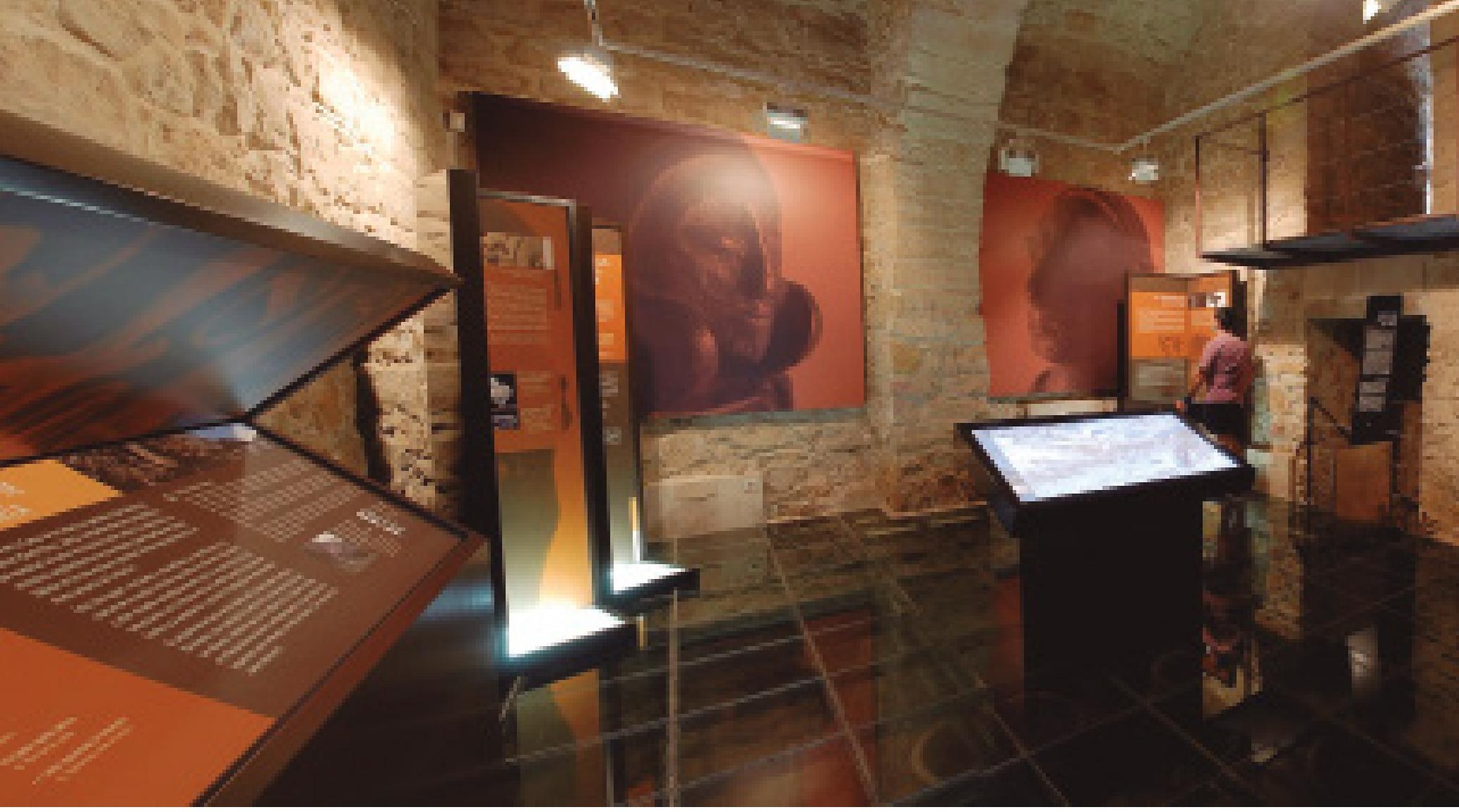

El TM del Condado se crea, por tanto, para paliar estas debilidades y potenciar sus oportunidades y fortalezas. Así comenzaba el proyecto, para el que se acordó que cada pueblo contara con un pequeño edificio que girase alrededor de una temática, convirtiendo así esta región en un gran museo que uniera su patrimonio con su territorio, desde la Prehistoria hasta sus ecosistemas actuales. La red de centros expositivos de nueva apertura al público fue de ocho:

1. Centro de Interpretación El Condado de Santisteban (Santisteban del Puerto): este primer centro es la puerta del TM y, por lo tanto, tiene por objetivo presentar todo lo que los visitantes verán desde este pueblo hasta el último de los ocho municipios contenidos en el TM. Sus exposiciones contienen todas las épocas históricas, partiendo desde una huella de dinosaurio hasta la batalla de las Navas de Tolosa, pasando por la Prehistoria, los íberos, los romanos, o la época islámica, todas presentes, además, en Santisteban del Puerto.

2.Centro de Interpretación Ciudad Fortificada de Giribaile (Vilches): este centro incluye la puesta en valor de asentamientos prehistóricos, una muralla íbera y un castillo medieval. Los visitantes tienen la posibilidad de recorrer el centro de interpretación, y, luego, ir a cada uno de los sitios arqueológicos para una mayor comprensión.

3. Centro de Interpretación Pablo de Olavide y las nuevas poblaciones (Arquillos): Pablo de Olavide y Jáuregui, natural de la ciudad de Lima en Perú, obtuvo el encargo del rey Carlos III de repoblar la zona de Sierra Morena. En Arquillos hay un itinerario que recorre partes de su vida.

4. Centro de Interpretación del aceite de oliva (Navas de San Juan): este producto es la base económica de la región, y en el centro se muestra cómo se produce, con herramientas interactivas, materiales y audiovisuales.

5. Museo Ibérico Cueva de la Lobera (Castellar): además de la exposición de los restos arqueológicos de exvotos íberos (Fig. 5) con audiovisuales y pantallas interactivas con su explicación, se realiza una visita a la cueva donde fueron hallados los restos.

Figura 5. Museo Ibérico en Castellar. Recuperado de http://blogterritoriomuseo.blogspot.com/2012/12/las-visitas-llegan-territorio-museo.html, 2019. 
6. Centro de Interpretación Historia de Sorihuela del Guadalimar (Sorihuela): este centro se distribuye en vertical por las distintas plantas de la Torre del Homenaje de una antigua fortaleza almohade. Además, desde arriba se contempla el pueblo y el entorno como un mirador.

7. Centro de Interpretación Mirador de Jorge Manrique (Chiclana de Segura): uno de los poetas más importantes de la literatura española del siglo XV, vivió y escribió en el castillo de Chiclana. El Centro narra, a través de múltiples paneles, pantallas interactivas y audiovisuales, incluso en formato de holograma en 3D, la faceta de poeta y de guerrero de Jorge Manrique en el contexto de las guerras internas de Castilla por su trono.

8. Centro de Interpretación de los Ecosistemas de El Condado de Jaén (Montizón): es el único centro al aire libre, siendo la flora y fauna las protagonistas, donde con diversos paneles se insta a proteger el patrimonio natural del Condado.

ASODECO, además, gestiona redes sociales como su web, blog y Facebook en activo, publicando las actividades culturales que se convocan en estos pueblos en relación con su patrimonio y el TM, como rutas turísticas, visitas de integración sociocultural para colectivos en minoría, los cambios de horarios de apertura, etc (ver Figura 5).

Actualmente este TM encuentra diversos obstáculos para su evolución y éxito debido a la escasez de recursos económicos, y al personal laboral insuficiente para gestionar el proyecto. Incluso uno de los centros ha sufrido un ataque de vandalismo y está cerrado temporalmente, y los horarios de apertura se reducen cada vez más. En el 2019 solo hay tres centros de siete que abren los sábados por la mañana (Castellar, Chiclana y Santisteban), cuando en el fin de semana se suelen atraer más visitantes. Mientras en el 2016 los centros tuvieron 1660 visitas, en el 2019 hasta el mes de septiembre estas se redujeron casi a la mitad, con 837 visitas. Es por todo ello que las negociaciones entre ASODECO y los ayuntamientos se van a retomar próximamente para mejorar la situación, según explicó Lorenzo Sáez.

\section{Análisis comparativo de los tres casos}

Se ha desarrollado mediante una matriz comparativa para contrastar las similitudes y especificidades de los casos estudiados (ver Tabla 4).

\section{Discusión}

En términos generales, se observan similitudes en los tres casos de TM, comenzando por la ausencia de un plan de interpretación. Ningún caso ha publicado su plan en artículos o en redes sociales. A pesar de que se observan algunas condiciones propuestas en el modelo, como la existencia de una organización temática que orienta al visitante, no existe un guion general que articule o defina claramente el territorio.

En los tres proyectos se ha planteado la existencia de una puerta, unas ventanas y unos caminos temáticos, lo cual demuestra que existe una organización del espacio orientada a brindar una oferta clara a los visitantes. Asimismo, es importante anotar que, los casos de Argentina y España cuentan con una estructura organizativa interna con unidades administrativas, las cuales mantienen un programa de eventos y ofrecen servicios a los visitantes. Esto demuestra la importancia de contar con una administración institucional a cargo de la activación y el mantenimiento del modelo de gestión. Por ejemplo, en Alghero no existe información acerca de las actividades vigentes y, no cuenta con estructura organizativa.

Otro aspecto que llama la atención a partir de los casos, es la participación activa y protagónica de la población local. Por un lado, se podría determinar a través de los servicios brindados por los negocios locales a los visitantes y, por otro, mediante la 
Tabla 4. Análisis comparativo con puntaje asignado a los tres casos reales de Territorio-museo (TM).

\section{Característi- cas de TM}

Tiene una estructura organizativa

Tiene un plan de
interpretación
territorial

territorial

Participación activa y protagónica de la población

\section{Tiene una} «puerta»

Tiene ventanas temáticas

iene caminos temáticos

Tiene un programa de eventos

0 puntos

Sí, contiene algunas rutas por recorridos históricos concretos, como por las murallas, o por el patrimonio natural, como la visita a la galería subterránea.

1 punto

Desconocida su actividad actual

Tiene servicios

Desconocida su actividad actual, pero en el inicio contó con empresas turísticas, alimentarias y comerciantes que pudieron haber ofrecido servicios.

0 puntos

\section{Argentina}

\section{España}

Sí, pero hasta donde se conoce, es difusa Sí, dentro de la Universidad Nacional de enrevesada por la falta de una estruc- Catamarca.

1 punto

No se conoce, pero se podría asumir que sí, dado que cuenta con elementos de un TM.

0 puntos

Sí, tanto desde la comunidad universitaria como desde la población local que ahí vive y muestra al público sus tradiciones locales.

1 puntos

Sí, el CRI, desde donde se informa del resto de centros y actividades dentro del TM.

1 punto

Sí, aunque no se definen en el proyecto por separado, parece haber tres temas: patrimonio natural, como el del parque botánico, patrimonio intangible constituido por las tradiciones de la comunidad local en el mercado y el circuito del Quirquincho, y patrimonio arqueológico, distribuido entre centros y museos de sitio.

1 punto

Sí, contiene visitas orientadas a temas concretos, como el circuito del Quirquincho, el parque botánico o la ruta por el arte rupestre.

1 punto

Sí, se publican regularmente en la red social de Facebook.

1 punto

En la red social explicitan el transporte público que lleva al TM, y hay comercios, como mercados artesanales.

1 punto

1 punto
Sí, la gestión se articula entre ASODECO y Ayuntamientos (8 municipios agrupados en una comarca denominada El Condado). Hay cargos concretos dedicados al TM.

1 punto

No se conoce, pero se podría asumir que sí, dado que cuenta con elementos de un TM.

0 puntos

Solo se conoce la participación de una parte de la población local desde la Asociación y sus miembros, y desde las distintas administraciones públicas.

0 puntos

Sí, el Centro de Interpretación de El Condado de Santisteban, desde donde se informa del resto de centros y actividades dentro del TM, y que engloba las diversas épocas históricas contenidas.

1 punto

Sí, son ocho, una ventana por cada pueblo, según lo que ofrezca históricamente cada uno ( $y$, en menor medida, lo que ofrezcan sus recursos naturales y patrimonio cultural). A su vez, dentro de cada municipio se abren distintas temáticas.

1 punto

Sí, contiene visitas y rutas orientadas a temas concretos en cada uno de los ocho municipios, como el circuito por la vida de Pablo de Olavide, o por la de Jorge Manrique, entre otros mencionados.

1 punto

Sí, se publican regularmente en la red social de Facebook, mientras que en el blog no hay actualizaciones este año.

1 punto

En la web explicitan alojamientos, restaurantes y otros servicios para usuarios dentro de los pueblos. 
organización y asistencia a eventos. Sobre lo primero, tan solo destaca el TM de Laguna Blanca, ya que cuenta con un mercado de productos locales, mientras que existe la duda de si en el TM de Jaén se cuenta con negocios referentes al aceite de oliva de la zona. En Alghero se mencionaba la participación de comercios locales, pero no hay más información al respecto (Miró \& Padró, 2000). Sobre lo segundo, sí que hay una gran labor de organización y participación en eventos de diversa naturaleza en los casos argentino y español, como ya se mencionó. En este sentido, también hay que destacar la participación de la comunidad científica universitaria de Catamarca, que, además de investigar en el TM, es otro tipo de protagonista social y local en la configuración de actividades.

La existencia de «puertas» de recepción de visitantes, «ventanas» y «caminos temáticos» en los tres casos denota una lectura integrada del patrimonio natural, cultural, tangible e intangible en el territorio. Esto contribuye a tener una mirada y valoración patrimonial positivas del entorno por parte de la población, pero también, puede generar conflictos en la priorización de los bienes naturales y culturales excluidos. Asimismo, dada la magnitud de la propuesta, queda por conocer la gestión de nivel micro de cada uno de los componentes.

Finalmente, sobre los puntajes, es interesante anotar que el caso que «no se cumple o se desconoce» el cumplimiento del TM, es, paradójicamente, el de Italia, el primero donde se quiso dar una lectura de TM a las múltiples intervenciones patrimoniales. Quizá la distancia en el tiempo contribuye a conocer menos acerca del estado actual de todo lo implementado. En definitiva, el proyecto parecía estar cumpliendo con el propósito de desarrollo local que define un TM, aunque no trataba de conservar el patrimonio y utilizarlo desde una perspectiva pedagógica, sino que se convertía en otra forma de turismo no sostenible.

Los otros dos casos, tienen puntajes similares, pudiendo considerarlos como «cumplimiento parcial o falta de información» del TM. Esta categoría podría sugerir la necesidad de atender ciertos temas como el plan de interpretación, la participación social y la oferta de servicios en general para los visitantes, que son los puntos débiles de los casos estudiados, para poder llegar a la categoría de «cumplimiento total» y configurar verdaderos Territorio Museo.

\section{Conclusiones}

El modelo de gestión de TM contiene, como ocurre en los ecomuseos, el espíritu de reforzar la identidad y la memoria de la población local, así como la búsqueda del desarrollo sostenible del lugar. Sin embargo, la presentación y revisión de casos ha permitido observar aspectos positivos y dificultades. Por ejemplo, la posibilidad de desdibujar fronteras políticas frente a otras maneras de compartir un territorio como el caso de Jaén en España, o la alternativa de ser un motor de desarrollo local rural como el caso de Argentina. Entre las principales dificultades, se encuentra la sostenibilidad del modelo de gestión. Quizá, la apuesta por una gestión a cargo de una institución educativa como el caso de Argentina permita asegurar recursos e investigaciones a largo plazo. Quizá una gestión a cargo de los gobiernos locales como el caso de España debiera asegurar institucionalidad y sostenibilidad, sin embargo, es importante tener en cuenta, las variables de alcance y voluntad política, y más en este caso, donde estas variables dependen de ocho entidades administrativas diferentes.

Un Territorio-museo debe unir la gestión de los distintos tipos de patrimonio de un territorio con su desarrollo sostenible. Esto supone la integración tanto de la comunidad humana que ahí vive y trabaja, como del paisaje y de todo su patrimonio, conformando así estas tres partes en una sola entidad a proteger y conservar. Además, la creación de un TM potencia los valores identitarios, económicos y sociales, como se 
ha comprobado en el análisis: según los objetivos de cada proyecto, se ha tratado de potenciar desde la idea de comunidad local con tradiciones ancestrales, la participación ciudadana y administrativa en la creación de nuevos espacios culturales, hasta la transformación de la oferta turística, desde el ocio más simple hasta un ocio cultural y pedagógico.

Sin embargo, para alcanzar estos valores y cumplir con la estrategia de desarrollo local del territorio, una de las cuestiones esenciales es que en un TM se debe plantear un plan de interpretación, con una serie de instrumentos que faciliten al visitante el aprendizaje y comprensión de los contenidos, límites y conexiones entre las partes del $\mathrm{TM}$, en un guion claro. Para conseguirlo, hace falta crear una estructura organizativa de gestión del TM, que además se mantenga en el tiempo y evolucione para avanzar siempre hacia adelante, manteniendo activo el TM y ofertando novedades.

También se debe crear una planificación territorial que integre el patrimonio con normativas de protección y difusión, en colaboración con las distintas figuras administrativas y con la misma ciudadanía, de forma que la idea de patrimonio sea una construcción colectiva, así como su gestión.

Cumpliendo todos estos factores, se obtiene el denominado Territorio-museo, concepto que se ha de consensuar en los distintos países, aplicando estas variables y características, y que puede ser una alternativa para revalorizar y poner en valor el patrimonio tangible e intangible de las zonas rurales.

\section{Referencias}

Ángeles, Ma. (2007). El museo más allá de sus límites. Procesos de musealización en el marco urbano y territorial. Oppidum: cuadernos de investigación 3, pp. 133-164.

Asociación para el Desarrollo Rural de la Comarca de El Condado (2019). Recuperado de http:// condadojaen.net/estrategia-de-desarrollo-del-plan-de-actuacion-global-en-el-condadode-jaen/

Consejo de Europa. (2005). Council of Europe Framework Convention on the Value of Cultural Heritage for Society. European Treaty Series - No. 199. Recuperado de https://www.coe.int/ en/web/conventions/full-list/-/conventions/treaty/199

Consejo Internacional de Monumentos y Sitios (1990). Carta Internacional para la Gestión del Patrimonio Arqueológico. Recuperado de: https:/www.icomos.org/images/DOCUMENTS/ Charters/arch_sp.pdf

Delfino, D. D., Barale, A., Díaz, R. A., Dupuy, S. J. P., Espiro, V. E., Pisani, M. G.... González, C. (2012). Territorio, Comunidad y Museo: Trayectorias desde el Museo Integral de la Reserva de Biosfera de Laguna Blanca (Dpto. Belén - Catamarca). III Encuentro de Museos Universitarios del Mercosur. Museos: memoria + creatividad = cambio social, pp. 1-11.

Instituto Andaluz del Patrimonio Histórico (2004). Carta de Cracovia. Principios para la Conservación y Restauración del Patrimonio Construido. Debate e investigación. Documento, 50(114115), pp. 1-3.

Miró, M. (2000). Construir el territorio museo: una propuesta para la gestión creativa del patrimonio cultural y natural en áreas rurales. En Actualidad Leader: Revista de desarrollo rural, 12, pp. 8-9.

Miró, M. \& Padró, J. (10 de mayo de 2000). El territorio museo de l'Alguer o la búsqueda de un turismo sostenible. [Mensaje en un blog] Recuperado de https://manelmiro.com/2009/07/01/ hola-mundo/

Miró, M. (2010). Interpretación, identidad y territorio. Una reflexión sobre el uso social del territorio. Boletín del Instituto Andaluz del Patrimonio Histórico, 5(18), pp. 33-37.

Miró, M. (1 de julio de 2009). Museo abierto y territorio museo, nuevos conceptos para la interpretación territorial del patrimonio cultural. Recuperado de https://manelmiro. 
devenir Vol. 7, N¹3, ENERO - JUNIO 2020, PP. 59-76 - ESTUDIOS I ISSN 2312-7562 | E-ISSN 2616-4949 UNIVERSIDAD NACIONAL DE INGENIERÍA, LIMA

doi: https://doi.org/10.21754/devenir.v7i13.762

com/2009/07/01/museo-abierto-y-territorio-museo-nuevos-conceptos-para-la-interpretacion-territorial-del-patrimonio-cultural/

Mora, J. \& Pimienta, M. (1996-2003). La Estrategia Territorial Europea (E.T.E.): Una concepción integradora y cohesionada del espacio. Norba: Revista de historia, 16(2), pp. 701-707.

Morales, J. (1998). La interpretación del patrimonio natural y cultural: todo un camino por recorrer. Boletín del Instituto Andaluz del Patrimonio Histórico, 6(25), pp. 150-157.

Museo Integral de Laguna Blanca, Catamarca, Argentina (2019). Recuperado de https://www. facebook.com/MuseolntegralLB/about/?ref=page_internal

Nieto, C. (2018). La apropiación social del patrimonio como elemento preventivo en la salvaguarda de los bienes culturales (tesis doctoral). Universidad Politécnica de Valencia, España.

Padró, J. (1996). La interpretación: un método dinámico para promover el uso social del Patrimonio Cultural y Natural. En Cuadernos PH Difusión del Patrimonio Histórico. Marcelo Martín y Javier Rodríguez (Coord). Número VII. Junta de Andalucía, Consejería de Cultura. Instituto Andaluz de Patrimonio Histórico y Editorial Comares, pp. 8-13.

Padró, J \& Miró, M. (2002). Gestión creativa y desarrollo territorial. Retos del patrimonio en el Siglo XXI. Periférica Internacional. Revista para el análisis de la cultura y el territorio, 1(3), 60-82. Recuperado de https://revistas.uca.es/index.php/periferica/article/view/1076

Ruiz, A. (2010). Interpretación y difusión: dos formas diferentes de ver el patrimonio. Arqueología y Territorio (7), pp. 165-177. 